\title{
Service Equity, Satisfaction, and Loyalty: From Transaction-Specific to Cumulative Evaluations
}

\author{
Line Lervik Olsen \\ Norwegian School of Management BI \\ Michael D. Johnson \\ University of Michigan Business School
}

Perceived equity is a key psychological reaction to the value that a service company provides. Yet equity research has focused on a customer's satisfaction with relatively well-defined service episodes or transactions. The authors argue and show that equity plays a very different role in affecting customer loyalty as one moves from transaction-specific to cumulative evaluations. Whereas equity is an important driver of transaction-specific satisfaction, equity is more of a post-satisfaction evaluation when modeling cumulative satisfaction. The research also demonstrates the superiority of cumulative evaluations toward explaining service loyalty and providing a balanced view of loyalty drivers. The results have important implications for how equity, satisfaction, and loyalty are modeled and managed in a service context.

Keywords: perceived equity; customer satisfaction, loyalty modeling 
Perceived equity is a customer's psychological reaction to the value that a service company provides. Given equity's central role in understanding marketing as an exchange, relationship-building process (Bagozzi 1975), it is no surprise that it is an important antecedent to customer satisfaction (Oliver and Swan 1989a, 1989b) and subsequent service usage (Bolton and Lemon 1999). Broad-based conceptions of equity, or perceived justice, are also central to a firm’s service recovery efforts (Smith and Bolton 1998; Smith, Bolton, and Wagner 1999).

Yet equity research has focused on a customer's satisfaction with a relatively welldefined usage occasion, consumption episode, or transaction. As our conception of service quality and satisfaction has grown over the past decade to include an emphasis on a customer's cumulative experience with a service provider (Dubé, Johnson, and Renaghan 1999; Garbarino and Johnson 1999; Johnson 2001; Johnson, Anderson and Fornell 1995; Johnson and Fornell 1991; Mittal and Kamakura 2001; Mittal, Kumar, and Tsiros 1999), equity’s role as an antecedent or consequence of satisfaction has become unclear. Although equity should drive transaction-specific satisfaction, we argue that equity plays a very different role in affecting perceptions of cumulative satisfaction and subsequent loyalty. Specifically, equity should have a more direct effect on loyalty.

This basic theoretical question has important practical implications for service practitioners. It reflects just how "top of mind” customer perceptions of equity really are. Contrasting the different conceptualizations of satisfaction is also central to understanding the impact that different components of a service offering have on loyalty. Service research suggests that human behavior, which is the pure service component of the service offering, is relatively more important when focusing on transactions as opposed to cumulative experience (Roos 1999; Stauss and Weinlich 1997). Moreover, cumulative equity and satisfaction should explain more variation in service loyalty (Johnson, Anderson, and Fornell 1995).

We study these questions using a quasi-experimental study of banking services. Different models are contrasted using data where the research instrument transitioned from a transactionspecific measurement of equity and satisfaction to a cumulative conceptualization of equity and satisfaction. We posit and find that equity is more top of mind when the evaluation is transaction based. When the evaluation is more cumulative, the role that equity plays in a satisfaction and loyalty model depends on whether or not customers have a reason to complain. Even when measuring cumulative satisfaction, equity may be an antecedent to customer satisfaction among those customers who are relatively dissatisfied and have a reason to complain (as due to a recent decline in service or increase in prices). This has important implications for how equity, satisfaction, and loyalty are modeled in an applied setting as companies use the output of a satisfaction model to allocate resources for quality improvement.

We first describe the two views of satisfaction in more detail and develop alternative models that relate equity and satisfaction to loyalty. We test these models using a two (transaction-specific satisfaction versus cumulative satisfaction) by two (reason to complain versus no reason to complain) quasi-experimental design. After establishing the causality in each condition, we expand the models to include the effects of service quality, product quality, and price on satisfaction and equity in order to test other predictions and illustrate the implications.

\section{TWO VIEWS OF SATISFACTION}


Two different conceptualizations of customer satisfaction have evolved over the past decade (Johnson 2001). Transaction-specific satisfaction dominated the marketing and consumer behavior literature up through the early 1990s (for reviews, see Oliver 1997; Yi 1991). This approach defines satisfaction as a customer's evaluation of his or her experience with and reactions to a particular product transaction, episode, or service encounter. Since the early 1990s, service and satisfaction research has grown to include an emphasis on cumulative satisfaction, defined as a customer's overall evaluation of a product or service provider to date (Johnson, Anderson, and Fornell 1995; Johnson and Fornell 1991). This cumulative satisfaction is central to recent national satisfaction index models in Sweden (Fornell 1992), the United States (Fornell et al. 1996), Norway (Johnson et al. 2001), and the European Union (Eklöf 2000).

These different conceptualizations are more complementary than competing as they serve different purposes (Johnson 2001). One advantage of transaction-specific measures is that they capture the complex psychological reactions that customers have to a product's or service provider's performance on a given occasion or over a given time period (Oliver 1997). Another advantage is that they allow companies to better track changes in performance that result from internal changes and/or quality improvements. When a manager makes changes in response to customer feedback, the effectiveness of those changes are more likely to affect customers' perceptions of their most recent episode or experience with the service provider. In contrast, it takes time for quality changes to affect more cumulative evaluations (Johnson, Anderson, and Fornell 1995).

Cumulative evaluations leave the time period of evaluation open. In the national index surveys cited above, customers are asked to consider all of their experiences to date when evaluating their satisfaction with a product or service (Fornell et al. 1996). Cumulative satisfaction recognizes that customers rely on their entire experience when forming intentions and making repurchase decisions. Thus, one advantage of cumulative evaluations is that they should better predict customers' intentions and behavior. The recent emphasis on cumulative satisfaction reflects a growing interest in understanding customer evaluations and relationships over time (Garbarino and Johnson

1999; Mittal and Kamakura 2001; Mittal, Kumar, and Tsiros 1999). For example, Mittal, Kumar, and Tsiros (1999) compared the drivers of satisfaction and behavioral intentions for vehicle owners 3 to 4 months after purchase of the vehicle (initial consumption period) and 21 months later (later consumption period) using more open (cumulative) evaluations. They found that service satisfaction has a greater impact on intentions earlier in the consumption history, whereas product satisfaction has a greater impact later on.

\section{EQUITY, SATISFACTION, AND LOYALTY}

Oliver (1997) defines equity as a "fairness, rightness, or deservingness comparison to other entities, whether real or imaginary, individual or collective, person or nonperson” (p. 196). Equity theory's relevance to marketing has been recognized for some time (Huppertz, Arenson, and Evans 1978). Stemming from social exchange theory (Adams 1965; Homans 1961), the underlying assumption is that interpersonal interactions are repetitive and evolve over time. Equity is closely related to the concept of reciprocity in market exchange relationships (Bagozzi 1975), suggesting that it can be conceptualized as a relatively cumulative perception. 
Nevertheless, the tradition in marketing and consumer research has been to measure equity perceptions in a relatively transaction-specific fashion (Huppertz, Arenson, and Evans 1978; Oliver and Swan 1989a, 1989b). Others have compared the explanatory power of equity to expectancy value, attribution, performance, and disconfirmation constructs (Oliver and DeSarbo 1988). Bolton and Lemon (1999) investigated payment equity in ongoing exchanges, whereas Tax, Brown, and Chandrashekaran (1998) showed equity's relevance in service recovery situations within relationship marketing. Yet little attention has been paid to the entire history of shared interactions, which is critical to understanding intentions and future behavior (Andreassen and Lervik 1999; Heide and Miner 1992).

Following Bolton and Lemon (1999) and Oliver (1997), we focus specifically on the distributive dimension of equity. Our understanding of distributive equity rests on Homans's (1961) rule of justice, where a person's rewards in exchange should be proportional to his or her investments. Equity is the customer's evaluation of what is fair or right based on a comparison of outcomes relative to inputs

(Bolton and Lemon 1999; Huppertz, Arenson, and Evans 1978). Accordingly, we operationalize distributive equity using measures of fairness and outcomes received relative to inputs made.

Previous research has shown distributive equity to be an antecedent to product or service satisfaction (Bolton and Lemon 1999; Oliver and Swan 1989a, 1989b). Customers incur certain prices or costs in exchange for a certain level of quality (or usage in Bolton and Lemon's cellular communication and entertainment service contexts). Distributive equity is the customer's reaction to these inputs to outputs or fairness. Equity, in turn, affects the customer's overall evaluation of the product or service provider, or customer satisfaction. But as argued below, this prediction and finding is predicated on a transaction-specific view of both the equity and satisfaction constructs.

Distributive equity operates in a fashion similar to perceived value (Fornell et al. 1996).We agree, however, with Bolton and Lemon that value may be a broader construct than distributive equity. Fornell et al. (1996) defined value as the ratio of quality received for price or prices paid, whereas distributive equity is more the customer's psychological reaction to inputs versus outputs and resulting fairness.

\section{Transaction-Specific Equity and Satisfaction}

We expect distributive equity to play a very different role in driving satisfaction and loyalty depending on the transaction-specific versus cumulative nature of the constructs involved. Consistent with prior research, we expect satisfaction to mediate the effects of equity on loyalty when equity and satisfaction are transaction specific. Loyalty in this case is a behavioral intentions construct. As shown on the left side of Figure 1, equity affects satisfaction, which in turn affects loyalty. We label this the equity first model. Our discussion is restricted for now to full mediation models. The reason, quite simply, is to avoid saturating the construct relationships to provide a stronger test of causality.

Theoretically, transaction-specific equity is a more bottom-up or concrete evaluation.

Within the context of a particular transaction or service episode, customers put forth so much to get so much. It is natural that this input versus output or perceived equity is evaluated as the service unfolds. In contrast, satisfaction with the episode or transaction is a post hoc or 
retrospective evaluation. Thus, satisfaction should be directly influenced by perceived equity. The main difference between this model and previous ones is that disconfirmation of expectations is no longer a separate driver of transaction-specific satisfaction (Oliver and Swan 1989a). Rather, it becomes one of multiple reflective measures of the satisfaction construct (see Johnson, Anderson, and Fornell 1995 for a discussion).

\section{Cumulative Equity and Satisfaction}

Although prior research has argued for and supported the equity-first model, we expect the sequence of cause and effect to change when both equity and satisfaction are measured in a more cumulative fashion. As shown to the right side of Figure 1, we posit that equity mediates the effect of satisfaction on loyalty in this case, which we call the satisfaction-first model. At the heart of the argument is that cumulative satisfaction is an inherently more reflective, attitudetype construct (Johnson, Anderson, and Fornell 2001). It is the customer's stored overall evaluation of his or her purchase and consumption experience to date with a product or service provider.

As long as customers are relatively satisfied with the goods and services that they purchase and consume, this stored evaluation serves as an anchor within a relatively top-down evaluation process. Perceived equity is no longer the starting point in the process. Rather, equity becomes an evaluation that customers are more likely to make as they approach the repurchase phase of the purchase-consumption-repurchase cycle. Following Johnson (1998), explicit judgments such as equity help to bridge the gap between satisfaction and repurchase decisions. As a result, equity should have a more direct effect on loyalty than does satisfaction. In the satisfaction-first model, customers draw upon their cumulative satisfaction when evaluating distributive equity, which in turn should impact loyalty. Put differently, equity is conceptually closer and more relevant to the consideration of one's behavior intentions (loyalty) in the context of cumulative evaluations.

This argument presumes, however, that customers are relatively satisfied with the product or service in question. That is, there is no reason to actively monitor distributive equity. We distinguish here between customers who are dissatisfied and have an explicit reason to complain (as with respect to the prices they pay or quality they receive) versus those who are relatively satisfied and have no reason to complain. We focus on "reason to complain" versus complaining customers per se for the simple reason that not all customers who are dissatisfied and potentially looking to leave actually complain.

If customers are relatively dissatisfied and have an explicit reason to complain, the proposed relationship may not hold. Being dissatisfied to the point where you have a reason to complain implies that the customer is no longer anchoring on a stored, overall evaluation of their experience. Rather, these customers are in a more active problem-solving or bottom-up evaluation process (Howard 1977). In contrast to transaction-specific evaluations, equity becomes the starting point in cumulative evaluations because of the customers' need to more actively monitor outputs relative to inputs. Thus, when customers are relatively dissatisfied and have a reason to complain, we expect equity and satisfaction to behave more as they do in the case of transaction-specific satisfaction. Following Oliver and Swan (1989a, 1989b) and Bolton and Lemon (1999), equity should be an antecedent to satisfaction and subsequent loyalty for 
these customers. This is consistent with Smith, Bolton, and Wagner's (1999) argument that a lack of equity among complaining customers is an important driver of satisfaction.

Overall, we predict that the nature of the causal relationship linking cumulative evaluations of equity, satisfaction, and loyalty is moderated by the customer's level of satisfaction and resulting reason to complain. We do not expect this to be the case for transaction-specific operationalizations of the distributive equity and satisfaction constructs, which is consistent with Oliver's (1997) view of transaction-specific satisfaction being a postepisodic (versus stored) evaluation. An alternative argument is that the difference between the transaction specific and cumulative constructs is minor compared to the difference between customers who do or do not have a reason to complain and actively reevaluate the fairness of the exchange relationship. That is, the equity-first model may be more universally applicable to dissatisfied customers with a reason to complain, whereas the satisfaction-first model may be more applicable to satisfied customers with no reason to complain. If this were the case, the level of satisfaction involved should moderate previous support for the equity-first model.

\section{The Impact of Service}

Whether customers are evaluating service episodes or more cumulative experiences should also have a direct effect on just what drives satisfaction and subsequent loyalty. Contrast the pure service component of the service offering (such as the service provider's understanding of customer needs and willingness to help) with the product and price components (such as the bank's facilities, interest rates, and fees). Prior research on the critical incident technique (Roos 1999; Stauss and Weinlich 1997) suggests that when the research focus is on a particular service episode or incident, the emphasis is on "observable human activity" (Flanagan 1954), which in this case is the service provider. What people tend to remember about particular service episodes or transactions is the service component of the overall service offering.

This suggests that transaction-specific surveys of equity and satisfaction may increase the relative impact that the pure service component has on loyalty. In contrast, cumulative evaluations of equity and satisfaction are more reflective and removed from the human interaction. We expect, as a result, that the impact of service vis-à-vis product and price is higher for a transaction-specific survey than for a cumulative survey. This prediction is consistent with the Mittal, Kumar, and Tsiros (1999) study described earlier. Recall that these authors found product satisfaction to have a greater impact on behavior intentions relative to service satisfaction as the consumption experience continued to unfold. Whereas these authors use the same type of evaluation over a shorter or longer consumption experience, our study uses different types of evaluation per se (transaction-specific versus cumulative).

\section{Differences in Loyalty Explained}

Our contrast of transaction-specific and cumulative satisfaction constructs also provides a direct test of the ability of these different evaluations to predict loyalty. It has been argued, albeit not shown, that cumulative evaluations are better predictors of loyalty than are transactionspecific evaluations (Johnson, Anderson, and Fornell 1995). Recall that this prediction is based on the argument that customers rely on all of their experiences to date when deciding what to 
buy or recommend to others. However, this difference has been presumed rather than explicitly tested in prior studies.

\section{Hypotheses}

Based on our discussion, we posit the following hypotheses:

Hypothesis 1. Satisfaction mediates the effect of equity on loyalty under the following conditions:

(a) Equity and satisfaction are transaction specific, and customers are relatively satisfied with no reason to complain.

(b) Equity and satisfaction are transaction specific, and customers are relatively dissatisfied with a reason to complain.

(c) Equity and satisfaction are cumulative, and customers are relatively dissatisfied with a reason to complain.

Hypothesis 2. Equity mediates the effect of satisfaction on loyalty when equity and satisfaction are cumulative and customers are relatively satisfied with no reason to complain.

Hypothesis 3. The impact of service on loyalty increases relative to the impact of product and price when evaluations are transaction specific as opposed to cumulative.

Hypothesis 4. Cumulative equity and satisfaction explain greater variation in loyalty than do transaction specific equity and satisfaction.

\section{EMPIRICAL STUDY}

\section{Research Design and Survey Data}

The study was designed as a quasi-experiment using an annual, national survey of Norwegian banks. Whereas transaction-specific data were collected in one year, cumulative data were collected the next year. We divided the customers in each survey into two segments, those with a reason to complain and those without, based on self-reports. The result is a two (transaction specific versus cumulative) by two (reason to complain or no reason to complain) between-subjects design.

The measures in the two surveys were kept as comparable as possible. The overriding difference was that, question by question, respondents were asked to consider the last experience the customer had with his or her bank in the transaction-specific survey versus their overall experience in the cumulative survey. For example, for the satisfaction question, the transactionspecific survey asked, "How satisfied or dissatisfied were you the last time you visited the bank?” In the cumulative survey, customers were asked, "How satisfied or dissatisfied are you overall with the bank?” Table 1 presents translations of the original Norwegian questions for all constructs as well as the 10-point scales that were used. We recognize that our two loyalty measures (likelihood of repurchase and likelihood of positive word-of-mouth) are potentially distinct behavioral intentions. Given their high correlation across samples, we model them as reflective measures of an overall loyalty construct.

The data were collected in the fall and winter of 1998 (transaction-specific survey) and 1999 (cumulative survey) as part of the Norwegian Customer Satisfaction Barometer using a professional marketing research firm. The interviewers used computer-assisted telephone 
interviews (CATI) both years. The respondents were drawn from randomly sampled households based on the closest birthday and range between the age of 18 and 85 . The interviewer made up to three callbacks, and each interview lasted approximately $15 \mathrm{~min}$. In the 1998 sample, there were 156 customers in the reason-to-complain category ( $45 \%$ male/55\% female, average age of 43, 57\% with more than a high school education). The 1998 sample contained 739 customers with no reason to complain ( $46 \%$ male $/ 54 \%$ female, average age of $50,36 \%$ with more than a high school education). In the 1999 sample, there were 264 customers in the reason to complain category ( $51 \%$ male/49\% female, average age of $45,46 \%$ with more than a high school education). Finally, the 1999 sample contained 638 customers with no reason to complain (49\% male/51\% female, average age of $49,43 \%$ with more than a high school education).

\section{Estimating the Structural Equation Models}

Two popular methods for estimating the SEM models with latent variables proposed here are covariance structure analysis (CSA) using LISREL and partial least squares. The aim of CSA is to explain relationships. Based on maximum likelihood estimation, it is particularly well suited to evaluating the relative fit of competing theoretical models (Bagozzi and Yi 1994). CSA is also well suited to conducting the multigroup analysis required to determine if the causal models for our four populations of customers are indeed different. In contrast, partial least squares (PLS) is an iterative estimation procedure that integrates principal-components analysis with multiple regression (Fornell and Cha 1994; Wold 1966). Whereas CSA explains covariance, the objective of PLS is to explain variance in the endogenous variables in a satisfaction model that has bottomline managerial relevance (such as satisfaction or loyalty). Thus, PLS is particularly well suited to operationalizing quality, satisfaction, and loyalty models in an applied setting (Johnson and Gustafsson 2000; Steenkamp and van Trijp 1996).

We use both of these estimation methods. CSA (using LISREL 8.30 software) is used first to conduct the multigroup tests. We then use both CSA and PLS to test between the equityfirst versus satisfaction-first models in Figure 1 to assure that our findings are robust to the estimation method and fitting objective used (Kujala and Johnson 1993). For brevity, we summarize the CSA results and focus on the PLS results. (Details of the CSA results are available from the authors.) Finally, we use PLS to operationalize expanded versions of the models that include the effects of service quality, product quality, and price on equity, satisfaction, and loyalty in order to test Hypotheses 3 and 4.

\section{Summary of the Multigroup Analysis}

Following Bagozzi (1994) and Bollen (1989), the multigroup analysis was conducted in a stepwise fashion. We first performed tests to determine whether the same measurement model holds for each group. The factor pattern and loadings were not statistically different across the groups, which is consistent with the argument that the overriding change in the survey from year to year was the transaction- specific versus cumulative nature of the evaluations.

We then tested the groups' structured means to identify differences in the levels of the latent variables. Using the transaction specific/no reason to complain as the comparison group, we found that the two groups with reason to complain scored significantly lower on all three latent variables (equity, satisfaction, and loyalty differences equal $-2.10,-1.63$, and -4.87 for the 
transaction-specific, reason-to-complain group, and -3.06, -1.27 , and -0.99 for the cumulative, reason-to-complain group). This supports the fact that our respondents with a reason to complain are systematically lower on all three constructs in the model. The cumulative, no-reason-tocomplain sample tends to score somewhat higher than the transaction-specific, no reason-tocomplain sample on loyalty (0.39) and slightly lower on perceived equity and satisfaction $(-1.67$ and -0.25). The differences are, however, much smaller than those involving the groups with or without reason to complain. Finally, we tested whether the traditional equity-first model holds for each sample. The chi-square tests suggest that the causal models are different across the groups.

\section{The Equity-First Versus \\ Satisfaction-First Models}

Our next step is to analyze the groups separately to see whether the traditional equity-first model or alternative satisfaction-first model is the better fitting model. We estimated the models for each group using CSA (LISREL) and then using PLS in the reflective mode. As satisfaction and loyalty data demonstrate negative skewness (Fornell 1995), we first obtained asymptotic variance/covariance matrices (normal scores) for each group so as not to violate the basic assumptions for running LISREL. The LISREL fit statistics for the two models across the four groups are shown in Table 2.

Our focus is on the relative fit of the two models for each sample, as we have constrained the analysis to only allow for full mediation. Full mediation avoids saturating the models, thus providing a stronger test of the competing causal arguments. (In a subsequent analysis, we relax this constraint.) For the two transaction-specific samples, the results support the traditional equity-first model. This is consistent with previous support for the model in the service quality and satisfaction literature (Bolton and Lemon 1999; Oliver and Swan 1989a, 1989b; Smith and Bolton 1998). We also find support for the equity-first model for that segment of customers who provide cumulative evaluations and have a reason to complain. However, the proposed satisfaction-first model is superior for the cumulative satisfaction sample with no reason to complain. These results support Hypotheses 1 and 2. Overall, this suggests that a different causal relationship holds for equity, satisfaction, and loyalty for the majority of subjects who evaluate equity and satisfaction as cumulative constructs - those who are relatively satisfied, have no reason to complain, and presumably are not actively monitoring distributive equity.

The same models were estimated using PLS in the reflective mode (Wold 1966). Fornell and Cha (1994) provided guidelines to apply when determining the quality of the models based on the output of a reflective PLS analysis. One is communality, or the square of the measurement loadings, which should exceed 50\% (loadings $>$.707) to ensure that at least half of the variance in the observed variables is shared with the construct. The average communality measures exceed the critical value for each model tested. The second criterion used to evaluate the validity of the measurement model, specifically the discriminant validity of the model, is to explore whether each LV (latent variable) or construct shares more variance with its MVs (measurement variables) than it does with other constructs in the model. This is examined by looking at the percentage of MV-loadings that exceed the LV-correlations. In this case, there were none. Thus, 
consistent with the LISREL findings, the PLS results support the validity of the measurement model.

Of primary interest in the PLS output is the variation explained and the size and significance of the path coefficients (Johnson et al. 2001).We use jackknifing to evaluate significance for the PLS path coefficients (Fornell and Barclay 1993). The path coefficients were significant and positive for each model and sample. (We defer more detailed discussion of the path coefficients to the next section when the models are expanded to include product quality, service quality, price, and the direct effects of both equity and satisfaction on loyalty.) The equity-first model explains greater variation in loyalty than the satisfaction-first model for the transaction-specific, no-reason-to-complain sample (34.2\% versus $17.6 \%)$. The same is true for the transaction-specific, reason-to-complain sample (33.8\% versus $21.5 \%$ ) and the cumulative satisfaction, reason-to-complain sample (57.1\% versus $51.6 \%$ ). In contrast, the equity-first model explains less variation in loyalty than the proposed satisfaction-first model for the cumulative satisfaction, no-reason-to-complain sample (33.5\% versus 37.8\%). The PLS results are thus consistent with the LISREL results. The equity-first model is supported in three of the four samples, whereas the satisfaction-first model is supported among those customers who evaluate cumulative equity and satisfaction and have no particular reason to complain.

\section{Operationalizing the Full Model}

Having established the appropriate causal sequence for each sample, we now expand the models to include the drivers of equity and satisfaction. This full model, presented in Figure 2, includes the possibility of partial mediation involving equity, satisfaction, and loyalty. We include partial mediation in these models for two reasons. First, allowing both equity and satisfaction to explain variation in loyalty provides a direct test of Hypothesis 4. Second, partial mediation is common in attitude models (Bagozzi 1994), of which satisfaction models are one variation (Johnson et al. 2001). PLS was used to operationalize the full model. The measures for price, product, and service are shown in Table 1 . These measures remain very comparable from 1998 to 1999. The exception is for the product construct. Both surveys use a product measure related to facilities and equipment. The 1998 survey uses two customer information-related questions that are condensed into a single written communication question for 1999, whereas the later survey adds a question on the timing of products and services. The price, product, and service questions also change from a 1 (very dissatisfied) to 10 (very satisfied) scale in 1998 to a 1 (very bad) to 10 (very good) scale in 1999.

As the reliability and discriminant validity of the measurement models are strongly supported in each case, we focus on the predictive ability of the models and the size and significance of the path coefficients (based on jackknife estimates). Table 3 presents the path coefficients and the variation explained in the latent variables by sample population.

The path coefficients illustrate just how equity and satisfaction work together to mediate the effects of service, product, and price on loyalty. Notice, for example, that service affects loyalty primarily through its effect on distributive equity. As service quality is the best available proxy for social equity in the model, and social equity is a primary determinant of distributive equity (Festinger 1954), this result has face validity. 
The most interesting observation is that the impact of product quality and price does increase relative to the impact of service when moving from transaction-specific to cumulative evaluations. As predicted, personal interactions with service people are more salient in the context of a particular service episode. Because cumulative evaluations are more reflective and removed from the purchase or consumption episode, consumers consider a more balanced set of influences. Price affects loyalty primarily through its impact on satisfaction, with one exception. For those cumulative satisfaction respondents with a reason to complain, the effect is primarily through distributive equity. This suggests that customers who are more cumulatively dissatisfied are relatively more concerned with the cost part of the equity trade-off, at least for the banks studied here.

To test Hypothesis 3, we examine the total impact of the drivers on the customer loyalty construct. These total effects are particularly important to managers who use impact and performance measures to set priorities for quality improvement (Johnson and Gustafsson 2000). The total effects for service, product, and price are shown in Figure 3. Although service quality is the most important driver in each case, as customer evaluations of the banks are more removed from a particular transaction or episode, service decreases in importance relative to product and price. That service is relatively more important when the period of evaluation is more constrained is consistent with Mittal, Kumar, and Tsiros’s (1999) results.

Finally, the predictive power of the models provides strong support for Hypothesis 4 . More variation is explained in the two cumulative satisfaction models (45\% and 63\%) compared with the two transaction-specific satisfaction models (35\% and 34\%). This is consistent with the purported advantage of cumulative satisfaction over transaction-specific satisfaction-its ability to predict (Fornell et al. 1996; Johnson, Anderson, and Fornell 1995). Where the equity-first model is appropriate (transaction specific and/or those with reason to complain), the models explain more variation in satisfaction than in equity. For the cumulative satisfaction sample with no reason to complain, the satisfaction-first model explains more variation in equity than

satisfaction. This is natural as the variation explained in these two constructs depends on whether equity explains satisfaction or vice versa.

\section{CONCLUSIONS AND DISCUSSION}

Our study explored the role that equity and customer satisfaction play in explaining customer loyalty for banking services. We proposed and supported systematic differences in how these constructs work as one moves from perceptions of service episodes to more cumulative evaluations. In the course of our research, we also explored how the drivers of loyalty and the ability to predict loyalty vary from episodic or transaction-specific evaluations to cumulative evaluations. Using a quasi-experimental design and national survey data, our study is the first to systematically examine these issues.

Prior research, conducted in the context of transactions or service episodes, supports a relationship where perceived equity, as the psychological reaction to a firm's value proposition, affects loyalty through satisfaction. We argue and show that this is not the case for most of the customers who evaluate equity and satisfaction in a more cumulative fashion. For those customers who are relatively satisfied with their service provider and have no particular reason to complain, equity is not actively monitored. Rather than being an antecedent to customer 
satisfaction in a bottom-up evaluation process, cumulative satisfaction is the anchor in a more top-down evaluation process. Equity is a judgment that bridges the gap between satisfaction and behavior intentions. However, for those customers who are dissatisfied and have a reason to complain, equity is more top-of-mind, even when making cumulative evaluations. As a result, equity is once again a driver rather than a consequence of satisfaction.

These findings have important implications for how service companies both model and manage equity, satisfaction, and loyalty. Many companies have moved to include more cumulative surveys in their customer information systems. This means, however, that perceptions of equity may need to be modeled very differently than in the past. The structural model may be dependent on the type of relationship that the service company has with its customers. For those customers where the relationship is relatively strong, equity is not particularly top-of-mind and more likely considered at the repurchase stage. Here a model that links satisfaction to equity to loyalty is more appropriate. For those customers where the relationship is strained, equity is more likely to directly influence overall evaluations of customer satisfaction. Here a model that links equity to satisfaction to loyalty is more appropriate.

The difference in models has implications for how customer relationships are managed. When customers are dissatisfied to the point where they have a reason to complain, the focus should be on improving perceptions of equity or fairness per se. Recall that perceived equity is central to a firm's service recovery efforts (Smith and Bolton 1998). A study by Smith, Bolton, and Wagner (1999) suggests that service recovery should be tailored to "fit the crime" so to speak. That is, the type or nature of the service failure or cause of dissatisfaction should dictate what service recovery method is appropriate. Consider a customer who has experienced a rude or embarrassing behavior from a service provider. What the customer really needs is an apology. When the service failure results in an economic rather than social loss, such as being overcharged for a service, then monetary compensation is appropriate.

In contrast, the strategy for maintaining relationships where customers are relatively satisfied and have no reason to complain is quite different. Here the goal is to maintain a topdown evaluation process. The focus is more on reinforcing a customer's existing satisfaction and loyalty and removing any "points of pain” or triggers that could create dissatisfaction and start customers down a potential switching path (Roos 1999). Providing these customers with information and communication about new and future services is also critical as both future and relative attractiveness influence customers' loyalty intentions (Andreassen and Lervik 1999).

We also predicted and found that the type of evaluations that customers make affect the impact that price and product have on loyalty vis-à-vis the pure service component of a service offering. In the context of a service episode or transaction, the impact of "people" is particularly salient. When evaluating their experiences to date, customers are more affected by a balance of price, product, and service. This has significant implications for the priority-setting process. This process generally looks for those drivers of satisfaction and loyalty where performance is weak and impact is high (Johnson and Gustafsson 2000). Our results show that the type of evaluations one uses affects these impact scores, thus influencing the priority-setting process.

Our final finding supports the contention that cumulative evaluations are better predictors of customers' loyalty intentions. Because customers consider all of their experiences rather than just a single episode or transaction when making repurchase decisions, cumulative evaluations 
should be better predictors of loyalty. Although previously argued (Fornell et al. 1996; Johnson, Anderson, and Fornell 1995), this prediction has not been tested. Our findings support this prediction in the context of banking services. The variation explained in loyalty increases from $35 \%$ and $34 \%$ for our transaction-specific samples to $45 \%$ and $63 \%$ for our cumulative samples.

The primary implication of this finding is that managers should focus more on cumulative evaluations when setting priorities for quality improvement. Our results suggest that cumulative evaluations provide a more balanced set of impact scores that are better predictors of loyalty. Transaction-specific evaluations overemphasize service vis-à-vis price and product, which could lead to a misallocation of resources. At the same time, it is important to remember that transaction-specific and cumulative satisfaction were developed with different goals in mind and are more complementary than competing. The transaction-specific evaluations capture the complexity of customers' psychological reactions to a particular product or service provider for a given occasion or consumption episode. Moreover, as argued earlier, transaction-specific evaluations should be more sensitive to changes in perceived quality. If a manager is trying to evaluate whether a given intervention or process improvement has had an effect, it will show up sooner in transaction-specific evaluations. This suggests that there is significant value in maintaining both transaction-specific evaluations and cumulative evaluations within a company’s customer information system (Johnson and Gustafsson 2000).

An important advantage of our quasi-experimental study is that we focus on the actual experiences of representative samples of bank customers. Naturally, quasi-experiments have their limitations. Our design manipulates transaction-specific versus cumulative evaluation between 2 years of data collection. This confounds the manipulation with the year in which the data were collected. With respect to the price, product, and service questions, there is also a change in scale (although not scale points) from year to year. However, neither one of these differences provides a ready explanation for our findings. Another limitation of using crosssectional surveys is that the measures in our database share a common method-related variance. This likely inflates the covariance across the measures and the estimated impacts in the models. Keep in mind, however, that our focus is on relative differences across samples rather than the absolute size of any particular effect. We also focus on a single service industry-banks. Although financial services are an important service industry, it will be important to test out predictions in other categories as well. Finally, our loyalty construct is a survey-based measure of behavior intentions, not actual behavior. Extending our research to the effects of actual loyalty and profitability is a natural direction for future research. 
FIGURE 1

Competing Equity, Satisfaction, and Loyalty Models

The Equity-First Model

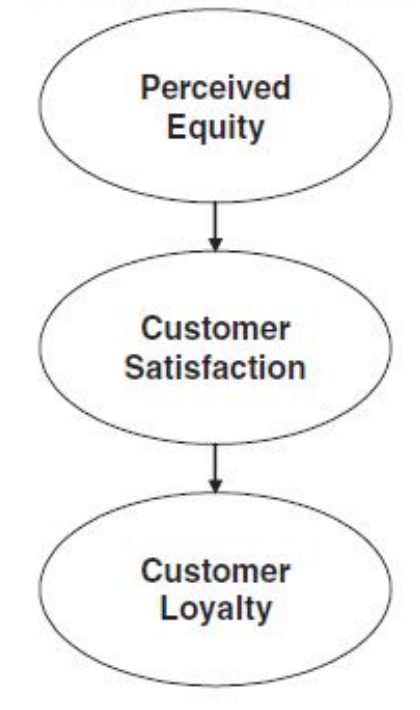

The Satisfaction-First Model

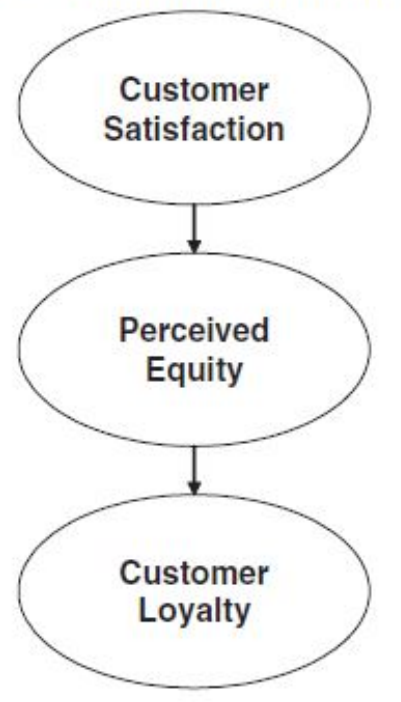

FIGURE 2

Expanded Service Quality, Satisfaction, and Loyalty Model

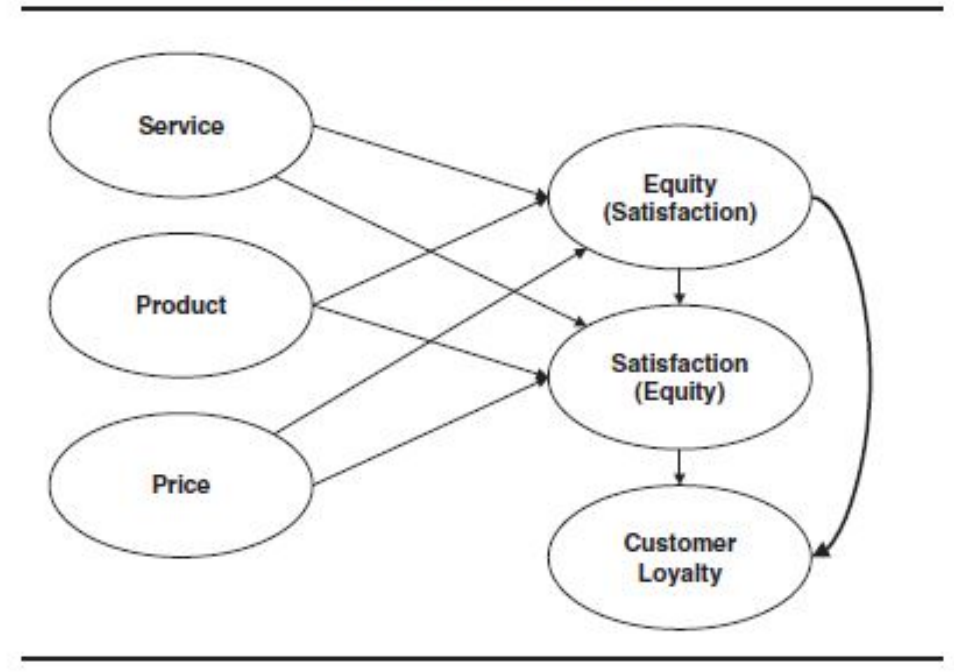


FIGURE 3

Total Effects of Service, Product, and Price on Bank Loyalty

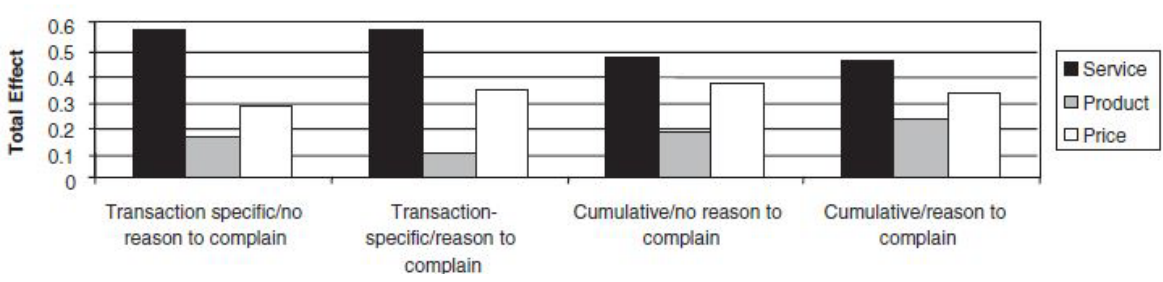


TABLE 1

Latent Variables, Survey Measures, and Scales

\begin{tabular}{|c|c|c|}
\hline Latent Variable & Transaction-Specific Measures (1998) & Cumulative Measures (I999) \\
\hline Equity & $\begin{array}{l}\text { "During my last experience with Bank X, I received the output } \\
\text { that I needed relative to my input." Scale: } 1 \text { (totally } \\
\text { disagree) to } 10 \text { (totally agree) } \\
\text { "I was treated fairly the last time I was in touch with the bank." } \\
\text { Scale: I (totally disagree) to } 10 \text { (totally agree) }\end{array}$ & $\begin{array}{l}\text { "To what degree is your output larger than your input when } \\
\text { you make use of Bank X's services?" Scale: } 1 \text { (very low } \\
\text { degree) to } 10 \text { (very high degree) } \\
\text { "To what degree do you think the bank treats you fairly?" } \\
\text { Scale: } 1 \text { (very low degree) to } 10 \text { (very high degree) }\end{array}$ \\
\hline Satisfaction & $\begin{array}{l}\text { "Think about an ideal bank. Looking back at your last experi- } \\
\text { ence with the bank, how far or close do you think Bank X } \\
\text { was to the ideal bank?" Scale: } 1 \text { (very far) to } 10 \text { (very close) } \\
\text { "To what degree did the bank fall short of or exceed your } \\
\text { expectations last time?" Scale: } 1 \text { (fell short of expectations) } \\
\text { to } 10 \text { (exceeded expectations) } \\
\text { "How satisfied or dissatisfied were you the last time you } \\
\text { visited the bank?" Scale: } 1 \text { (very dissatisfied) to } 10 \\
\text { (very satisfied) }\end{array}$ & $\begin{array}{l}\text { "Think about an ideal bank. Looking back at your } \\
\text { experiences so far with the bank, how far from or close } \\
\text { to do you think Bank X is to the ideal bank?" Scale: } \\
1 \text { (very far) to } 10 \text { (very close) } \\
\text { "To what degree does the bank fall short of or exceed your } \\
\text { expectations overall?" Scale: } 1 \text { (falls short of expecta- } \\
\text { tions) to } 10 \text { (exceeds expectations) } \\
\text { "How satisfied or dissatisfied are you overall with the } \\
\text { bank?" Scale: } 1 \text { (very dissatisfied) to } 10 \text { (very satisfied) }\end{array}$ \\
\hline Loyalty & $\begin{array}{l}\text { "How likely or unlikely is it that you would choose Bank X the } \\
\text { next time you are in need of bank services?" Scale: } \\
1=\text { (very unlikely) to } 10 \text { (very likely) } \\
\text { "How likely is it that you will speak favorably of the bank to } \\
\text { others?" Scale: } 1 \text { (very unlikely) to } 10 \text { (very likely) }\end{array}$ & $\begin{array}{l}\text { "How likely or unlikely is it that you would choose Bank X } \\
\text { the next time you are in need of bank services?" Scale: } \\
1=\text { (very unlikely) to } 10 \text { (very likely) } \\
\text { "How likely is it that you will speak favorably of the bank } \\
\text { to others?" Scale: } 1 \text { (very unlikely) to } 10 \text { (very likely) }\end{array}$ \\
\hline Prices $^{\mathrm{a}}$ & $\begin{array}{l}\text { "How satisfied or dissatisfied were you with the prices of Bank } \\
\text { X's services compared to their quality?" } \\
\text { "How satisfied or dissatisfied were you with the prices of Bank } \\
\text { X's services compared to other banks?" }\end{array}$ & $\begin{array}{l}\text { "How good or bad are Bank X's services priced compared } \\
\text { to their quality?" } \\
\text { "Compared to other banks, how good or badly priced are } \\
\text { Bank X's services?" }\end{array}$ \\
\hline Product $^{\mathrm{a}}$ & $\begin{array}{l}\text { "How satisfied or dissatisfied were you with Bank X's accessi- } \\
\text { bility (in terms of facilities and equipment such as locations, } \\
\text { ATMs, phone, and internet)?" } \\
\text { "How satisfied or dissatisfied were you with the information } \\
\text { Bank X provides about the cost of different services?" } \\
\text { "How satisfied or dissatisfied were you with the other informa- } \\
\text { tion Bank X offers its customers?" }\end{array}$ & $\begin{array}{l}\text { "How good or bad are Bank X's equipment and facilities?" } \\
\text { "How good or bad is the written communication from } \\
\text { Bank X?" } \\
\text { "How good or bad is the timing of Bank X's products and } \\
\text { services?" }\end{array}$ \\
\hline Service $^{a}$ & $\begin{array}{l}\text { "How satisfied or dissatisfied were you with the way Bank X's } \\
\text { employees treated you the last time you were in the bank?" } \\
\text { "How satisfied or dissatisfied were you with Bank X's } \\
\text { employees' ability to create an environment of trust for } \\
\text { you as a customer?" } \\
\text { "How satisfied or dissatisfied were you with Bank X's } \\
\text { employees' ability to help you?" } \\
\text { "How satisfied or dissatisfied were you with Bank X's } \\
\text { employees' ability to understand your needs?" } \\
\text { "How satisfied or dissatisfied were you with Bank X's } \\
\text { employees' ability to provide the services quickly and } \\
\text { efficiently?" }\end{array}$ & $\begin{array}{l}\text { "How good or bad do you think Bank X treats its } \\
\text { customers?" } \\
\text { "How good or bad do you think Bank X's employees } \\
\text { are at creating an environment of trust for you as a } \\
\text { customer?" } \\
\text { "How good or bad do you think Bank X is at allocating } \\
\text { time to help their customers?" } \\
\text { "How good or bad do you think Bank X's employees are at } \\
\text { understanding customers needs?" } \\
\text { "How good or bad do you think Bank X's employees are at } \\
\text { providing quick service?" }\end{array}$ \\
\hline
\end{tabular}

a. Scale for 1998: 1 (very dissatisfied) to 10 (very satisfied); scale for 1999: 1 (very bad) to 10 (very good). 
TABLE 2

CSA Results by Sample and Model

\begin{tabular}{|c|c|c|c|c|c|c|c|c|}
\hline Sample & & $\begin{array}{c}\text { Chi-square } \\
\text { p-value }(\mathrm{df}=12)\end{array}$ & RMSEA & $S R M R$ & $G F I$ & $A G F I$ & $N N F I$ & CFI \\
\hline \multirow{2}{*}{$\begin{array}{l}\text { Transaction specific/ } \\
\text { no reason to complain }\end{array}$} & Equity first & $\chi^{2}=48.68 p<.001$ & .065 & .030 & .98 & .96 & .96 & .98 \\
\hline & Satisfaction first & $\chi^{2}=95.75 p<.001$ & .100 & .046 & .96 & .91 & .91 & .95 \\
\hline \multirow{2}{*}{$\begin{array}{l}\text { Transaction specific/ } \\
\text { reason to complain }\end{array}$} & Equity First & $\chi^{2}=41.20 p<.001$ & .13 & .061 & .93 & .84 & .88 & .93 \\
\hline & Satisfaction first & $\chi^{2}=46.72 p<.001$ & .13 & .065 & .92 & .82 & .86 & .92 \\
\hline \multirow{2}{*}{$\begin{array}{l}\text { Cumulative/ } \\
\text { reason to complain }\end{array}$} & Equity first & $\chi^{2}=32.32 p<.002$ & .050 & .026 & .99 & .97 & .98 & .99 \\
\hline & Satisfaction first & $\chi^{2}=23.13 p<.027$ & .039 & .021 & .99 & .98 & .99 & .99 \\
\hline \multirow{2}{*}{$\begin{array}{l}\text { Cumulative/ } \\
\text { reason to complain }\end{array}$} & Equity first & $\chi^{2}=29.31 p<.005$ & .071 & .034 & .97 & .93 & .96 & .98 \\
\hline & Satisfaction first & $\chi^{2}=29.40 p<.001$ & .077 & .033 & .97 & .41 & .96 & .98 \\
\hline
\end{tabular}

TABLE 3

Partial Least Squares Results for the Service Quality, Satisfaction, and Loyalty Model

\begin{tabular}{|c|c|c|c|c|}
\hline $\begin{array}{l}\text { Path Coefficients, } \\
\text { and Variation Explained }\end{array}$ & $\begin{array}{l}\text { Transaction Specific/ } \\
\text { No Reason to Complain }\end{array}$ & $\begin{array}{l}\text { Transaction Specificl } \\
\text { Reason to Complain }\end{array}$ & $\begin{array}{c}\text { Cumulativel } \\
\text { No Reason to Complain }\end{array}$ & $\begin{array}{c}\text { Cumulativel } \\
\text { Reason to Complain }\end{array}$ \\
\hline Service to equity & .453 & .622 & .361 & .398 \\
\hline Product to equity & .146 & $.026^{*}$ & .112 & .198 \\
\hline Price to equity & .090 & .200 & .195 & .336 \\
\hline Service to satisfaction & .370 & .235 & .324 & .244 \\
\hline Product to satisfaction & $.091 *$ & $.079 *$ & .148 & $.120^{*}$ \\
\hline Price to satisfaction & .237 & .241 & .346 & .128 \\
\hline Equity to satisfaction & .265 & .498 & - & .442 \\
\hline Satisfaction to equity & - & - & .232 & - \\
\hline Equity to loyalty & $.110^{* *}$ & $.048 *$ & .419 & .355 \\
\hline Satisfaction to loyalty & .521 & .550 & .333 & .495 \\
\hline$R^{2}$ equity & .342 & .498 & .521 & .544 \\
\hline$R^{2}$ satisfaction & .565 & .670 & .430 & .610 \\
\hline$R^{2}$ loyalty & .351 & .344 & .450 & .629 \\
\hline
\end{tabular}

NOTE: All path coefficients are significant at $p<.05$ unless otherwise noted.

${ }^{*}=$ not significant. ${ }^{* *}=$ significant at $p<.10$. 


\section{REFERENCES}

Adams, J. Stacy (1965), "Inequity in Social Exchange,” in Advances in Experimental Social Psychology, Vol.

2, Leonard Berkowitz, ed. New York: Academic Press, 267-99.

Andreassen, Tor Wallin and Line Lervik (1999), "Perceived Relative Attractiveness Today and

Tomorrow as Predictors of Future

Repurchase Intention,” Journal of Service Research, 2 (November), 164- 72.

Bagozzi, Richard P. (1975), “Marketing as Exchange,” Journal of Mar- keting, 39 (October), 3239.

Principles of (1994), "Structural Equation Models in Marketing Research: Basic Principles," in Richard P. Bagozzi, ed. Cambridge, MA: Blackwell, 317-85.

Marketing Research, and Youjae Yi (1994), “Advanced Topics in Structural Equation Models,” in Advanced

Methods of Marketing Research,

Richard P. Bagozzi, ed. Cambridge, MA: Blackwell, 1-52.

Bollen, Kenneth A. (1989), Structural Equations with Latent Variables. New York: John Wiley. Bolton, Ruth N. and Katherine N. Lemon (1999), “A Dynamic Model of Customers’ Usage of Services: Usage as an Antecedent and Consequence of Satisfaction,” Journal of Marketing Research, 36 (May), 171-86. Dubé, Laurette, Michael D. Johnson, and Leo Mark Renaghan (1999), “Adapting the QFD Approach to Extended Service

Transactions," Production and Operations Management, 8 (Fall), 301-17.

Eklöf, Jan A. (2000), European Customer Satisfaction Index Pan- European Telecommunication Sector Report-Based on the Pilot Studies 1999. Stockholm, Sweden: European Organization for Quality and European

Foundation for Quality Management.

Festinger, Leonard (1954), “A Theory of Social Comparison Processes,” Human Relation, 7, $117-40$.

Flanagan, John C. (1954), “The Critical Incident Technique,” Psychological Bulletin, 51 (July), 327-58.

Fornell, Claes (1992), “A National Customer Satisfaction Barometer: The Swedish Experience,” Journal of Marketing, 56

(January), 6-21. (1995), "The Quality of Economic Output: Empirical Generalizations about Its

Distribution and Association to Market Share,” Marketing Science, 14 (3), G203-11. and Donald W. Barclay (1993), “Jackknifing in PLS,” working paper, University of Michigan Business School, Ann Arbor.

Research, R and Jaesung Cha (1994), "Partial Least Squares," in Advanced Methods of Marketing Cambridge, MA: Blackwell, 52-78. ichard P. Bagozzi, ed. 
, Michael D. Johnson, Eugene W. Anderson, Jaesung Cha, and Barbara Everitt Bryant (1996), "The

American Customer

Satisfac- tion Index: Nature, Purpose and Findings,” Journal of Marketing, 60 (October), 7-18.

Garbarino, Ellen and Mark S. Johnson (1999), "The Different Roles of Satisfaction, Trust, and Commitment in Customer Relationships,” Journal of Marketing, 63 (April), 70-87.

Heide, Jan B. and A. S. Miner (1992), "The Shadow of the Future: Effects of Anticipated Interaction and

Frequency of Contact on Buyer-Seller Cooperation,” Academy of Management Journal, 35 (2), 265-91.

Homans, George C. (1961), Social Behavior: Its Elementary Forms. New York: Harcourt, Brace \& World.

Howard, John A. (1977), Consumer Behavior: Application of Theory. New York: McGraw-Hill. Huppertz J. W., S. J. Arenson, and R. H. Evans (1978), "An Application of Equity Theory to Buyer-Seller Exchange Situations,"

Journal of Marketing Research, 15 (May), 250-60.

Johnson, Michael D. (1998), Customer Orientation and Market Action. Upper Saddle River, NJ: Prentice

Hall.

(2001), “Customer Satisfaction,” in Neil J. Smelser and Paul B. Baltes, eds. International Encyclopedia of the Social \& Behavioral Sciences. Amsterdam, the Netherlands:

Elsevier, 3198-

202. , Eugene W. Anderson, and Claes Fornell (1995), "Rational and Adaptive Performance

Expectations in a Customer

Satisfaction Framework,” Journal of Consumer Research, 21 (March), 128-40. and Claes Fornell (1991), “A Framework for Comparing Customer Satisfaction across

Individuals and Product

Categories,” Journal of Economic Psychology, 12 (2), 267-86. and Anders Gustafsson (2000), Improving Customer Satisfaction, Loyalty and Profit: An

Integrated Measurement and

Management System. San Francisco: Jossey-Bass. Anders Gustafsson, Tor Wallin Andreassen, Line Lervik, and Jaesung Cha (2001), “The

Evolution and Future of the National Customer Satisfaction Index Models,” Journal of Economic Psychology, 22 (2), 217-45.

Kujala, Jouni T. and Michael D. Johnson (1993), "Price Knowledge and Search Behavior for Low Involvement Food Purchases,” Journal of Economic Psychology, 14 (2), 249-66. Mittal, Vikas and Wagner A. Kamakura (2001), "Satisfaction, Repurchase Intent, and Repurchase Behavior: Investigating the Moderating Effect of Customer Characteristics,” Journal of Marketing Research, 38 (February), 131-42. , Pankaj Kumar, and Michael Tsiros (1999), "Attribute-Level Performance, Satisfaction, and Behavioral Intentions over Time: A Consumption-System Approach,” Journal of Marketing, 63 (April), 88-101. 
Oliver, Richard L. (1997), Satisfaction: A Behavioral Perspective on the Consumer. New York: McGraw-

Hill. and Wayne DeSarbo (1988), "Response Determinants in Satisfaction Judgments," Journal

of Consumer Research, 14 (March), 495-507. and J. E. Swan (1989a), "Consumer Perceptions of Interpersonal Equity and Satisfaction

in Transactions: A Field Survey Approach,” Journal of Marketing, 53 (April), 21-35. and __ (1989b), "Equity and Disconfirmation Perceptions as Influences on Merchant

and Product Satisfaction," Journal of Consumer Research, 16 (December), 372-83.

Roos, Inger (1999), "Switching Processes in Customer Relationships," Journal of Service

Research, 2

(August), 68-85.

Smith, Amy and Ruth Bolton (1998), "An Experimental Investigation of Ongoing Customer

Reactions to

Service Failure and

Recovery Encounter: Paradox or Peril?” Journal of Service Research, 1 (August), 65-81. Smith, Amy K., Ruth N. Bolton, and Janet Wagner (1999), “A Model of Customer Satisfaction with Service

Encounters Involving

Failure and Recovery,” Journal of Marketing Research, 36 (August), 356-72.

Stauss, Bernd and B. Weinlich (1997), "Process-Oriented Measurement of Service Quality:

Applying the

Sequential Incident

Method," European Journal of Marketing, 31 (1), 33-55.

Steenkamp, Jan-Benedict E. M., and Hans C. M. van Trijp (1996), “Quality Guidance: A

Consumer-Based

Approach to Food

Quality Improvement using Partial Least Squares,” European Review of

Agricultural Economics, 23, 195-215.

Tax, Stephen S., Stephen W. Brown, and Murali Chandrashekaran (1998), “Customer

Evaluations of

Service Complaint

Experiences: Implications for Relationship Marketing,” Journal of Marketing, 62 (April), 6077.

Wold, Hermann (1966), "Estimation of Principal Components and Re- lated Models by Iterative Least Squares," in Multivariate Analysis: Proceedings of an International Symposium Held in Dayton,

Ohio, P. R. Krishnaiah, ed. New York: Academic Press, 391-420.

Yi, Yougae (1991), “A Critical Review of Customer Satisfaction,” in Review of Marketing 1990 Valarie

Zeithaml, ed. Chicago:

American Marketing Association, 68-123. 